\title{
A narrative review of exploring potential salivary biomarkers in respiratory diseases: still on its way
}

\author{
Chuan-Xiang Li $^{1,2,3 \#}$, Liu Zhang ${ }^{1,2 \#}$, Ya-Ru Yan ${ }^{1,2 \#}$, Yong-Jie Ding ${ }^{1,2}$, Ying-Ni Lin ${ }^{1,2}$, Jian-Ping Zhou ${ }^{1,2}$, \\ Ning Li ${ }^{1}$, Hong-Peng Li ${ }^{1,2}$, Shi-Qi Li ${ }^{1,2}$, Xian-Wen Sun ${ }^{1,2}$, Qing-Yun Li ${ }^{1,2}$ \\ ${ }^{1}$ Department of Respiratory and Critical Care Medicine, Ruijin Hospital, Shanghai Jiao Tong University School of Medicine, Shanghai, China; \\ ${ }^{2}$ Institute of Respiratory Medicine, Shanghai Jiao Tong University School of Medicine, Shanghai, China; ${ }^{3}$ Department of Respiratory and Critical \\ Care Medicine, Tongren Hospital Affiliated to Wuhan University, The Third Hospital of Wuhan, Wuhan, China \\ Contributions: (I) Conception and design: CX Li, L Zhang, YR Yan, XW Sun, QY Li; (II) Administrative support: QY Li; (III) Provision of study \\ materials or patients: CX Li, L Zhang, YR Yan, YJ Ding, YN Lin, QY Li; (IV) Collection and assembly of data: CX Li, JP Zhou, N Li, HP Li, SQ \\ Li, XW Sun, QY Li; (V) Data analysis and interpretation: CX Li, L Zhang, YR Yan, XW Sun, QY Li; (VI) Manuscript writing: All authors; (VII) \\ Final approval of manuscript: All authors. \\ \#These authors contributed equally to this work. \\ Correspondence to: Qing-Yun Li, MD, PhD. Department of Respiratory and Critical Care Medicine, Ruijin Hospital, Shanghai Jiao Tong University \\ School of Medicine, 197 Ruijin Er Road, Shanghai 200025, China. Email: liqingyun68@hotmail.com.
}

\begin{abstract}
Saliva is abundant with proteins, metabolites, DNA, and a diverse range of bacterial species. During the past two decades, saliva has emerged as a novel diagnostic and evaluation medium for several diseases. Collection of saliva samples is simple, minimally invasive, and convenient even in infants, children, and patients with anxious. Furthermore, with the development of hypersensitive techniques [e.g., microsensor arrays, enzyme-labeled immunosensors, nanoparticle-labeled immunosensors, capacitive or impedimetric immunosensors, magneto immunosensors, field effect transistor immunosensors, and surface enhanced Raman spectroscopy (SERS)], the sensitivity and accuracy of saliva diagnostic procedures have been improved. Nowadays, saliva has been used as a potential medium for several disease diagnosis and assessment, such as periodontitis, caries, cancers, diabetes mellitus, and cardiovascular diseases. Saliva has been used widely for studying microbiomics, genomics, transcriptomics, proteomics, and metabolomics of respiratory diseases, however, the use of salivary biomarkers for the diagnosis, prognosis, and monitoring of respiratory disease is still in its infancy. Herein, we review the progress of research on salivary biomarkers related to several respiratory diseases, including bronchial asthma, chronic obstructive pulmonary disease (COPD), obstructive sleep apnea (OSA), pneumonia, tuberculosis (TB), Langerhans cell histiocytosis (LCH) and cystic fibrosis (CF). Furthermore, several limitations of saliva test such as the lack of standard protocol for saliva collection and reasonable reference values for saliva test are also mentioned in this review.
\end{abstract}

Keywords: Saliva; biomarker; respiratory disease

Submitted Jan 31, 2021. Accepted for publication May 25, 2021.

doi: $10.21037 /$ jtd-21-202

View this article at: http://dx.doi.org/10.21037/jtd-21-202

\section{Introduction}

Saliva has been used widely for biomarker studies related to several diseases, such as periodontitis, caries, cancers, diabetes mellitus, and cardiovascular diseases because more than 2,000 types of proteins and peptides, 3,000 unique mRNAs, and 700 bacterial species have been detected in it (1-10).
Collection of saliva samples is simple, minimally invasive, and convenient even in infants, children, and anxious patients (11). With the development of hypersensitive techniques, such as microsensor arrays, enzyme-labeled immunosensors, nanoparticle-labeled immunosensors, capacitive or impedimetric immunosensors, magneto immunosensors, field 
effect transistor immunosensors (FET), and surface enhanced Raman spectroscopy (SERS) (10,12-15), the sensitivity and accuracy of diagnostic procedures have been improved. Nowadays, saliva has been used as a potential medium for disease diagnosis and assessment. However, exploration of salivary biomarkers for the diagnosis, monitoring, and prognosis of respiratory diseases is still in its infancy, although the first study on this topic was reported in 1977 (16). Thus, we reviewed the studies on potential saliva biomarkers related to respiratory diseases (Table 1 and Figure 1) and analyzed the progress and obstacles concerning this issue.

We present this paper in accordance with the Narrative Review reporting checklist (available at http://dx.doi. org/10.21037/jtd-21-202).

\section{Methods}

In this study, we searched the PubMed database to identify eligible studies on salivary biomarkers of respiratory diseases. The search terms used were "saliva" or "salivary" in combination with "respiratory disease," "asthma," "chronic obstructive pulmonary disease," "COPD," "obstructive sleep apnea," "OSA," "pneumonia," "tuberculosis," "TB," "lung cancer," or "lung carcinoma." Two of our investigators independently searched the databases and reviewed each of the retrieved articles. Any discrepancies were discussed and solved by the third investigator together with the two investigators. The last literature search was performed on Jan 20, 2021.

\section{Bronchial asthma}

Bronchial asthma is characterized by airway inflammation and hyperresponsiveness (17). Levels of cytokines and inflammatory proteins have been reported to be high in the saliva of patients with asthma $(15,18-20,60)$. Significant differences in the levels of biomarkers, including IL-8 (3,056.9 vs. $1,070.87 \mathrm{pg} / \mathrm{mL}, \mathrm{P}=0.008), \mathrm{IL}-10$ (24.60 vs. $15.82 \mathrm{pg} / \mathrm{mL}, \mathrm{P}=0.008)$, sCD163 (1,852.08 vs. 659.56, $\mathrm{P}=0.003)$, Eosinophil cationic protein (ECP) (486-845 vs. 246-467 $\mu \mathrm{g} / \mathrm{L}, \mathrm{P}<0.01)$, IL-5 ( $\mathrm{P}=0.003)$, IL-6 ( $\mathrm{P}=0.035)$, and VEGF ( $\mathrm{P}=0.016)$, were found between patients with asthma and controls $(18,20)$. In addition, salivary IL-8, IL-10, sCD163, ECP, and IP-10/CXCL10 levels were found to be correlated with the forced expiratory volume in $1 \mathrm{~s}$ (FEV1), fraction of exhaled nitric oxide (FeNO) levels, and exacerbation of asthma, which implies that these indicators could be used as potential biomarkers for monitoring airway obstruction and exacerbation of asthma $(15,18,20)$. Notably, Gaber et al. conducted a study on patients with aspirinintolerant asthma (AIA) and found that these patients showed a higher salivary cysteinyl-leukotriene (CysLT) level than did those with aspirin tolerant asthma (ATA; $144 v s$. $69 \mathrm{pg} / \mathrm{mL}, \mathrm{P}=0.007)$; therefore, salivary CysLT level could be a potential biomarker for diagnosing AIA (22).

Recently, a salivary microbiome study has demonstrated that patients with asthma have a higher salivary bacterial diversity than do controls (Shannon index: $2.12 \pm 0.23$ vs. $2.01 \pm 0.24, \mathrm{P}=0.013$; Pielou index: $0.81 \pm 0.04$ vs. $0.79 \pm 0.05, \mathrm{P}=0.01)$. The relative abundances of the genera Streptococcus $(13.0 \%$ vs. $18.3 \%, \mathrm{P}=0.003)$ and Veillonella (11.1\% vs. $8.0 \%, \mathrm{P}=0.002)$ were significantly different between the asthma and control groups (17). However, the pathophysiological mechanisms associated with these changes of salivary microbiomes in patients with asthma need to be studied further.

Additionally, saliva samples have been used as a source of DNA for epigenetic studies on asthma (61-63). An increase in DNA methylation in the promoterregulatory region of $\mathrm{PM} 20 \mathrm{D} 1$ in infant saliva was found to be associated with the occurrence of early childhood wheezing (21).

\section{Chronic obstructive pulmonary disease (COPD)}

COPD is characterized by progressive airflow obstruction and chronic airway inflammation. Few studies that focused on the inflammatory and oxidant stress-related factors indicated the importance of exploring potential biomarkers. Among the inflammatory factors (Table 1) investigated $(23,24,64,65)$, salivary IL- 8 and matrix metalloproteinase (MMP-9) levels showed a negative relationships with lung function $(\mathrm{P}=0.009$ and 0.003 , respectively) (24). An increase in salivary $\mathrm{C}$-reactive protein (CRP), PCT, and neutrophil elastase (NE) levels could predict the risk of acute exacerbation of COPD (AECOPD), but these biomarkers were not found to be suitable for evaluating the severity of COPD (23). With regard to the biomarkers of oxidative stress, it was found that salivary uric acid (UA) level in patients with COPD was 2.2 times higher than that in controls $(\mathrm{P}=0.05)$, while no difference in total antioxidant status (TAS), peroxidase level, and super oxide dismutase (SOD) level was found between groups (25).

During the past two decades, microbiomes have been hot spots of COPD research; however, studies on salivary 
Table 1 Summary of saliva studies in respiratory diseases

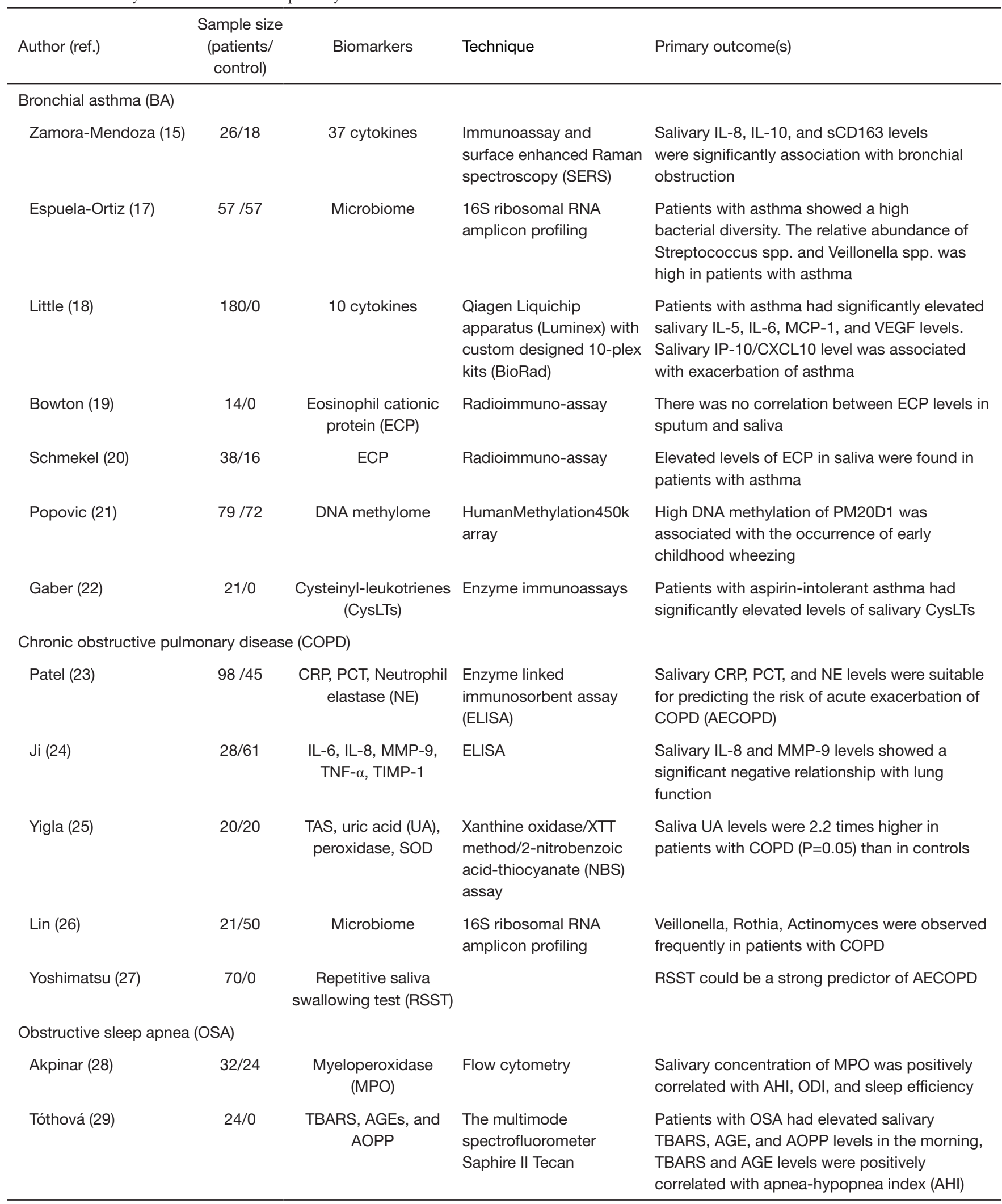

Table 1 (continued) 
Table 1 (continued)

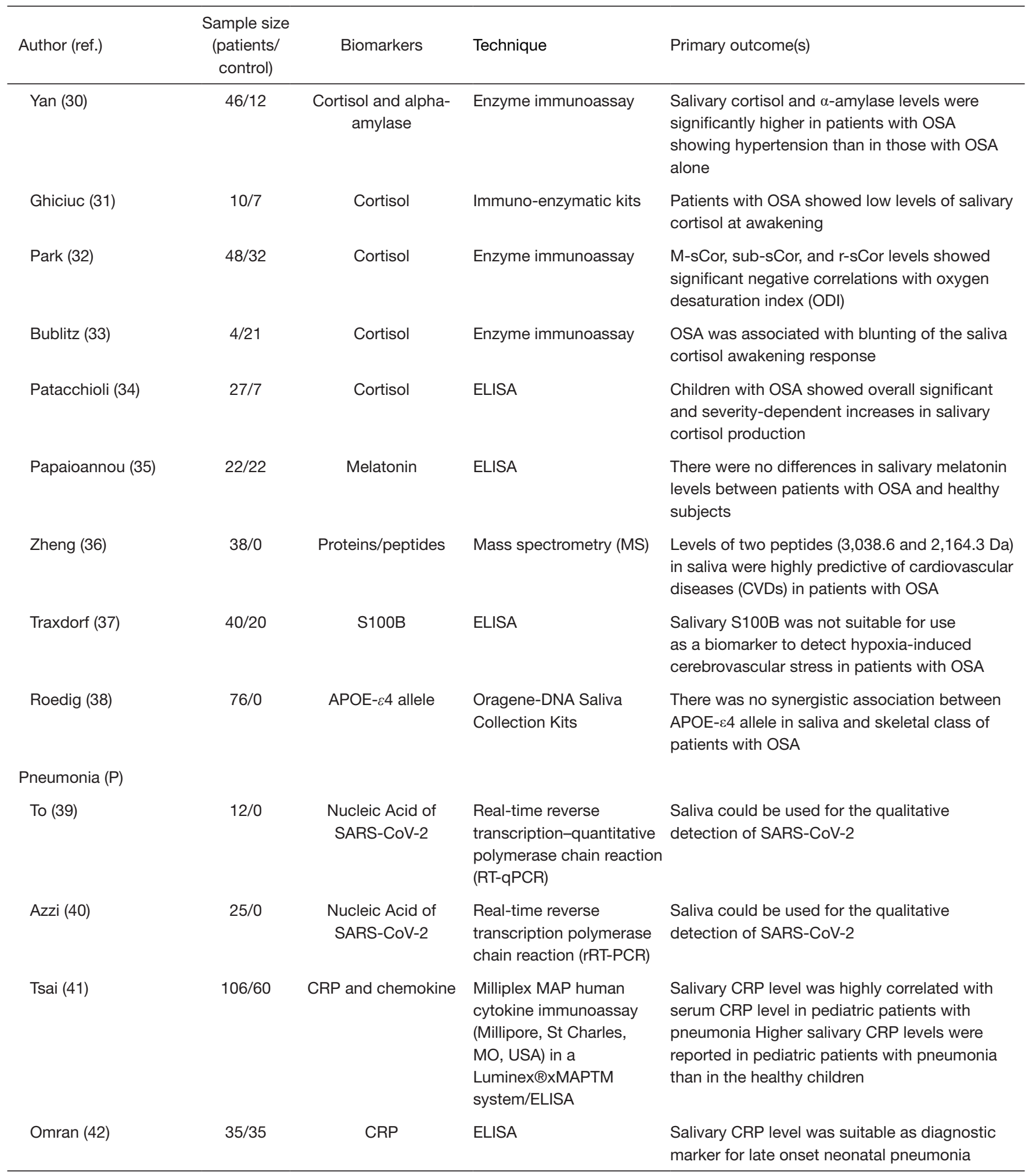

Table 1 (continued) 
Table 1 (continued)

\begin{tabular}{|c|c|c|c|c|}
\hline Author (ref.) & $\begin{array}{l}\text { Sample size } \\
\text { (patients/ } \\
\text { control) }\end{array}$ & Biomarkers & Technique & Primary outcome(s) \\
\hline \multicolumn{5}{|l|}{ Tuberculosis (TB) } \\
\hline Jacobs (44) & $18 / 33$ & 69 host markers & $\begin{array}{l}\text { Multiplex cytokine } \\
\text { platform }\end{array}$ & $\begin{array}{l}\text { A 5-maker combination of salivary IL- } 1 \beta \text {, } \\
\text { IL-23, ECM-1, HCC1 and fibrinogen could } \\
\text { help diagnose TB with a sensitivity } 88.9 \% \text { and } \\
\text { specificity of } 89.7 \%\end{array}$ \\
\hline Namuganga (45) & $39 / 39$ & 10 host markers & Luminex immunoassay & $\begin{array}{l}\text { A 3-marker model comprising of salivary G-CSF, } \\
\text { TNF- } \alpha \text { and VEGF was recommended for TB } \\
\text { diagnosis (sensitivity of } 63 \% \text { and specificity of } \\
63 \% \text { ) }\end{array}$ \\
\hline Phalane (46) & $11 / 27$ & 33 host markers & $\begin{array}{l}\text { Luminex Multiplex } \\
\text { Immunoassay }\end{array}$ & $\begin{array}{l}\text { A 5-marker combination of salivary IL-5, IL-6, } \\
\text { IL-15, TNF- } \alpha \text {, and CRP was recommended for } \\
\text { TB diagnosis (accurately predicted } 81.8 \% \text { of } \\
\text { the TB cases) }\end{array}$ \\
\hline Jacobs (47) & $32 / 72$ & 33 host markers & $\begin{array}{l}\text { Multiplex cytokine } \\
\text { platform }\end{array}$ & $\begin{array}{l}\text { A 7-marker combination of salivary CRP, ferritin, } \\
\text { serum amyloid P, MCP-1, } \\
\text { alpha-2-macroglobulin, fibrinogen, and tissue } \\
\text { plasminogen activator was recommended } \\
\text { for TB diagnosis (sensitivity of } 78.1 \% \text { and } \\
\text { specificity of } 83.3 \% \text { ) }\end{array}$ \\
\hline \multicolumn{5}{|l|}{ Lung cancer (LC) } \\
\hline Sun (5) & $3 / 3$ & Exosomes & $\begin{array}{l}\text { Western Blot (WB), } \\
\text { LC-MS/Mass } \\
\text { Spectrometry (MS) } \\
\text { analysis }\end{array}$ & $\begin{array}{l}11 \text { high potential salivary protein biomarkers } \\
\text { were identified }\end{array}$ \\
\hline Ding (6) & $68 / 41$ & EGFR & Droplet digital PCR & $\begin{array}{l}\text { Salivary cfDNA was found to be suitable for } \\
\text { detecting EGFR mutations }\end{array}$ \\
\hline Wei (50) & $66 / 0$ & EGFR & $\begin{array}{l}\text { Electric field-induced } \\
\text { release and measurement } \\
\text { (EFIRM) }\end{array}$ & $\begin{array}{l}\text { Salivary cfDNA was found to be suitable for } \\
\text { detecting EGFR mutations }\end{array}$ \\
\hline $\mathrm{Pu}(51)$ & $17 / 0$ & EGFR & EFIRM & $\begin{array}{l}\text { Salivary cfDNA was found to be suitable for } \\
\text { detecting EGFR mutations }\end{array}$ \\
\hline
\end{tabular}

Table 1 (continued) 
Table 1 (continued)

\begin{tabular}{|c|c|c|c|c|}
\hline Author (ref.) & $\begin{array}{l}\text { Sample size } \\
\text { (patients/ } \\
\text { control) }\end{array}$ & Biomarkers & Technique & Primary outcome(s) \\
\hline Wang (54) & $55 / 15$ & Microbiome & $\begin{array}{l}\text { 16S rDNA amplification } \\
\text { sequencing }\end{array}$ & $\begin{array}{l}\text { Patients with lung cancer had lower salivary } \\
\text { microbial diversity. Salivary Filifactor was a } \\
\text { potential bacterial biomarker }\end{array}$ \\
\hline Yan (56) & $61 / 25$ & Microbiome & $\begin{array}{l}\text { 16S rDNA amplification } \\
\text { sequencing }\end{array}$ & $\begin{array}{l}\text { Salivary Capnocytophaga and Veillonella } \\
\text { abundances were significantly increased in } \\
\text { patients with lung cancer }\end{array}$ \\
\hline \multicolumn{5}{|c|}{ Langerhans cell histiocytosis (LCH) } \\
\hline Preliasco (57) & $29 / 12$ & $\begin{array}{l}\mathrm{IL}-1 \mathrm{~b} \text { and } \\
\text { prostaglandin E2 } \\
\text { (PGE2) }\end{array}$ & $\begin{array}{l}\text { Enzyme Immune Assay } \\
\text { System }\end{array}$ & $\begin{array}{l}\text { Salivary IL-1b and PGE2 levels played a critical } \\
\text { role as markers of LCH disease progression }\end{array}$ \\
\hline \multicolumn{5}{|l|}{ Cystic fibrosis (CF) } \\
\hline
\end{tabular}

TAS, total antioxidant status; SOD, super oxide dismutase; M-sCor, morning salivary cortisol; n-sCor, night salivary cortisol; sub-sCor, m-sCor minus n-sCor; r-sCor, m-sCor/n-sCor; TBARS, thiobarbituric acid reacting substances; AOPP, advanced oxidation protein products; AGEs, advanced glycation end products.

microbiomes have only been conducted on patients with COPD showing periodontitis. These studies revealed that patients with periodontitis showing COPD had a significantly higher bacterial richness and diversity in saliva than did those with periodontitis alone (26).

\section{Obstructive sleep apnea (OSA)}

OSA is a common sleep disorder associated with breathing. The main pathophysiology of this disorder involves chronic intermittent hypoxia and sleep fragmentation, which are related to inflammation, oxidative stress, and sympathetic activation (66).
Several inflammatory and oxidative stress-related markers in saliva have been identified. In a previous study, patients with OSA showed a significantly higher salivary myeloperoxidase (MPO) level than did the controls $(\mathrm{P}<0.0001)$. The MPO level was found to be correlated with apnea-hypopnea index (AHI) and oxygen desaturation index (ODI; both $\mathrm{P}=0.0001$ ) (28). In another study, markers of high oxidative stress such as thiobarbituric acid reacting substances (TBARS), advanced oxidation protein products (AOPP), and advanced glycation end products (AGEs) were found in the saliva of patients with OSA in the morning, and TBARS and AGEs showed a positive correlation with AHI ( $\mathrm{r}=0.48$ and 0.49 , respectively; 


\begin{tabular}{|l|l|}
\hline \multicolumn{1}{|c|}{ Inconclusive } & Promising Biomarkers \\
\hline Salivary flow rate & CRP \\
pH, UA, Phosphate, TP, & Pathogen(SARS-COV-2) \\
Magnesium, Calcium, & \\
Alb, LDH & \\
Amylase & \\
\hline
\end{tabular}

\begin{tabular}{|l|}
\hline \multicolumn{1}{|c|}{ Promising Biomarkers } \\
Genomics \\
scfDNA for EGFR mutation detection \\
Transcriptomics \\
CCNI, EGFR, FGF19, FRS2, GREB1 \\
Proteomics: \\
HP, AZGP1, Human calprotectin \\
Microbiome: \\
Filifactor, Capnocytophaga,Veillonella \\
SERS \\
\hline \multicolumn{1}{c|}{ Inconclusive } \\
\hline Exosomal \\
\hline Negative Results \\
\hline Genomics \\
scfDNA for lung cancer diagnosis
\end{tabular}

\begin{tabular}{|c|c|}
\hline Negative Results & Promising Biomarkers \\
\hline $\begin{array}{l}\text { Melatonin } \\
\text { APOE- } 84 \text { allele } \\
\text { S100B }\end{array}$ & \multirow{3}{*}{$\begin{array}{l}\alpha \text {-amylase } \\
\text { TBARS, AGEs, AOPP } \\
\text { MPO } \\
\text { Two peptides(3038.6 /2164.3 Da) } \\
\text { Pepsin }\end{array}$} \\
\hline Inconclusive & \\
\hline Cortisol & \\
\hline
\end{tabular}

COPD Promising Biomarkers Negative Results

\section{IL-8, MMP-9}

NE,CRP, PCT(AECOPD)

UA

RSST

TDM for Theophylline
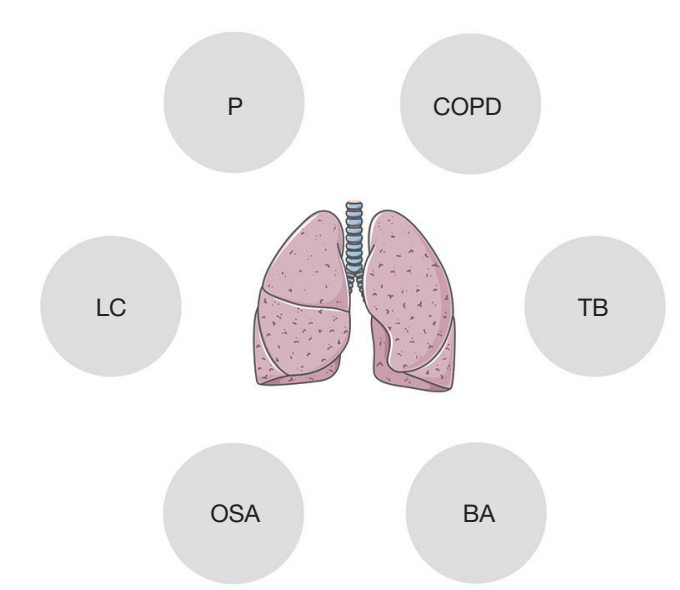

\begin{tabular}{|c|}
\hline \multicolumn{1}{|c|}{ Promising Biomarkers } \\
\hline Inflammatory biomarkers \\
Individual markers \\
IL-6,CRP, MIP-1 $\beta$, fractalkine ,A2M, \\
haptoglobin, fibrinogen, IL-16,IL-23 \\
Combination markers \\
G-CSF, TNF- $\alpha$ and VEGF \\
IL-5, IL-6, IL-15, TNF- $\alpha$, and CRP \\
IL-1 1 , IL-23, ECM-1, HCC1 and fibrinogen \\
CRP, ferritin, serum amyloid P, MCP-1, \\
alpha-2-macroglobulin, fibrinogen and \\
tissue plasminogen activator \\
\hline Negative Results \\
\hline TDM \\
Amikacin and Levofloxacin \\
\hline
\end{tabular}

\begin{tabular}{|l|l|}
\hline \multicolumn{1}{|c|}{ Promising Biomarkers } & \multicolumn{1}{|c|}{ Negative Results } \\
\hline Inflammatory biomarkers & eotaxin-1/CCL11 \\
IL-8, IL-10, Scd163, IP-10/ & RANTES/CCL5 \\
CXCL10, ECP & MIP-1b/CCL4, CXCL8, \\
Epigenomics & IL-1b, MCP-1/CCL2 \\
DNA methylation (PM20D1) & Inconclusive \\
Microbiome & IL-5, IL-6, MCP-1, VEGF \\
Cysteinyl-leukotrienes & \\
\hline
\end{tabular}

Figure 1 Potential of salivary biomarkers and their current state of validity. This figure includes the most common respiratory diseases: bronchial asthma (BA), chronic obstructive pulmonary disease (COPD), obstructive sleep apnea (OSA), Pneumonia (P), Tuberculosis (TB), and lung cancer (LC). For these diseases, a categorical system classifies the biomarkers as: promising, inconclusive or negative results based upon the findings of our work. Uric acid (UA), Total protein (TP), Albumin (Alb), Lactate dehydrogenase (LDH), C-reactive protein (CRP), neutrophil elastase (NE), Repetitive saliva swallowing test (RSST), Total antioxidant status (TAS), Super oxide dismutase (SOD), Therapeutic drug monitoring (TDM), Eosinophil cationic protein (ECP), Thiobarbituric acid reacting substances (TBARS), Advanced glycation end products (AGEs), Advanced oxidation protein products (AOPP), Myeloperoxidase (MPO), Surface Enhanced Raman Spectroscopy (SERS), Haptoglobin hp2 (HP), Zinc a2-glycoprotein (AZGP1).

$\mathrm{P}<0.05)$. Furthermore, treatment with continuous positive airway pressure (CPAP) could significantly decrease the morning salivary concentrations of TBARS, AOPP, and AGEs $(\mathrm{P}<0.05)(29)$.

Alfa-amylase ( $\alpha$-amylase) level is a biomarker of the activation of the sympathetic adrenomedullary (SAM) system. Salivary $\alpha$-amylase level was found to be higher in patients with moderate-to-severe OSA $(\mathrm{P}<0.01)$, and it showed a correlation with OSA severity (AHI, microarousal index, and the lowest pulse oxygen saturation). A cut-off value $(17.64 \mathrm{U} / \mathrm{mL})$ of salivary $\alpha$-amylase level could indicate the presence of moderate-to-severe OSA with the sensitivity of
$85 \%$ and specificity of $91 \%$ (30). In addition, saliva was also used to test cortisol levels in patients with OSA $(31,32,67)$. The blunting of the cortisol awakening response was reported in patients with OSA. The morning cortisol level tended to be lower in patients with OSA than in controls $(\mathrm{P}<0.05)$, and it showed a negative correlation with AHI $(\mathrm{P}<0.05)(32,33)$. However, in a special group of OSA, inconsistent results were reported. Patacchioli et al. reported that children with OSA showed significant and severity-dependent increases in salivary cortisol production (34). Moreover, patients with OSA showing hypertension also showed higher salivary cortisol levels than did those with OSA alone $(10.01 \pm 2.77 v s$. 
$5.52 \pm 1.90 \mathrm{ng} / \mathrm{mL}, \mathrm{P}<0.05)(30)$.

\section{Pneumonia}

Studies on saliva in patients with pneumonia mainly focus on the identification of pathogens. It has been reported that influenza virus A, Ebola virus, Cytomegalovirus, and Herpes simplex virus could be identified in salivary samples (68). During the pandemic of COVID-19, testing of saliva samples for severe acute respiratory syndrome coronavirus 2 (SARS-CoV-2) attracted a lot of attention because of the ease associated with self-collection and a decrease in the risk of exposure associated with the collection of nasopharyngeal or oropharyngeal samples by healthcare workers $(39,40,69-74)$. The coincidence rate for the detection of SARS-CoV-2 between salivary samples and nasopharyngeal swabs was $91.7-100 \%(39,40)$. The US Food and Drug Administration granted an emergency authorization for the use of the first saliva testing kits for the diagnosis of SARS-CoV-2 (75). It was also reported that salivary viral load was significantly correlated with COVID-19 severity and showed a superior ability over nasopharyngeal viral load as a predictor of mortality (AUC $=0.90)$ (69).

Other salivary indicators were also reported in studies on pneumonia. Serum CRP is a sensitive biomarker for pneumonia. It was reported that salivary CRP level was highly correlated with serum CRP level in pediatric patients with pneumonia $(r=0.679, \mathrm{P}<0.001)$. Higher salivary CRP level was reported in pediatric patients with pneumonia than in the healthy children $(48.77 \pm 5.52$ vs. $14.78 \pm 3.92 \mathrm{ng} / \mathrm{mL}$, $\mathrm{P}<0.001)(41)$. It was reported that an increase in salivary CRP level (cut-off value of $3.8 \mathrm{ng} / \mathrm{L}$ ) could help diagnose neonatal pneumonia with a sensitivity of $91.4 \%$ and a specificity of $80.9 \%$ in a study conducted by Omran et al. (42). Salivary CRP level could be a surrogate biomarker for serum CRP level in the diagnosis of pneumonia, especially in pediatric patients. However, the value of salivary CRP level in the diagnosis of different types of pneumonia has rarely been mentioned. Salivary flow rate $(\mathrm{P}=0.0001), \mathrm{pH}(\mathrm{P}=0.0498)$, and UA $(\mathrm{P}=0.048)$, phosphate $(\mathrm{P}=0.0437)$, and total protein $(\mathrm{P}=0.0128)$ levels changed significantly in children with pneumonia than in healthy children (43). It was also reported that the pathogenic bacteria present in the salivary samples collected before operation could be predictive of the risk of postoperative aspiration pneumonia (76). Finally, salivary sIgA level has been used to evaluate the efficacy of influenza vaccine (77).

\section{Tuberculosis (TB)}

Inflammatory and immune markers have been used in the diagnosis of TB $(44,78)$. In patients with TB, levels of several inflammatory biomarkers, including IFN- $\gamma$, IL- $1 \alpha$, IL-12 (p70), IL-13, IL-15, IL-17, fractalkine, GM-CSF, and EGF, in saliva samples were found to be significantly higher than those in serum samples $(45,46)$. Salivary IL-6, CRP, MIP-1 $\beta$, fractalkine, A2M, haptoglobin, fibrinogen, IL-16, and IL-23 levels are potentially valuable in the diagnosis of TB, with an AUC of $\geq 0.70(44,46,47)$. Furthermore, a combination of salivary biomarkers could improve the diagnostic accuracy of TB (44-47). For example, a fivemarker combination of IL-1 $\beta$, IL-23, ECM-1, HCC1, and fibrinogen could help diagnose TB with a sensitivity of $88.9 \%$ and a specificity of $89.7 \%$ (44). Furthermore, salivary proteomic analysis showed that there were differences between patients with active TB versus infected and uninfected contacts in terms of the composition of salivary protein and quantities of its components, including haptoglobin, alpha-1-acid glycoprotein 1 and 2, immunoglobulin gamma 4 chain, fibrinogens, dermcidin, glutathione synthetase, lactoylglutathione lyase, protein disulfide isomerase, triosephosphate isomerase, tropomyosin alpha 4, and ras GTPase-activating like protein (9).

\section{Lung cancer (LC)}

Some studies on LC have focused on genomics, transcriptomics, proteomics, and microbiomics of saliva. Saliva could act as the source of cell-free DNA (cfDNA) for the detection of EGFR mutations; the coincidence rate for the detection of EGFR mutations between salivary cfDNA and plasma cfDNA reached $83.78 \%$ (6), and a new technology named electric field-induced release and measurement (EFIRM) was used to detect EGFR mutations in saliva with an improved accuracy $(50,51)$. Levels of other salivary indicators such as transcriptomic biomarkers (e.g., BRAF, CCNI, EGRF, FGF19, FRS2, GREB1, and LZTS1), proteins (e.g., haptoglobin hp2, zinc $\alpha 2$-glycoproteinand human calprotectin), and exosomes (e.g., Aquaporin5 and Mucin-5B) were also found to be significantly different between patients with LC and control subjects, and this finding has potential diagnostic value for $\operatorname{LC}(5,52,53)$. For example, it was reported that a combination of five mRNA biomarkers (CCNI, EGFR, FGF19, FRS2, and GREB1) could differentiate patients with LC from normal control subjects with $93.75 \%$ sensitivity and $82.81 \%$ 
specificity, yielding an AUC value of 0.925 (52), and that salivary proteins including haptoglobin $\mathrm{hp} 2(\mathrm{HP})$, zinc $\alpha 2-$ glycoprotein (AZGP1), and human calprotectin could predict LC with a sensitivity of $88.5 \%$, a specificity of 92.3\%, and an AUC of $>0.90$ (53).

The link between cancer and microbes has been well established (79-82). Salivary microbiomics become another subject of growing interest with regard to LC studies. Low microbial diversity in the saliva of patients with LC has been reported (Shannon index, $\mathrm{P}=0.002$; Simpson index, $\mathrm{P}=0.033)$. Relative abundances of the genera Veillonella, Streptococcus, Prevotella, Bacteroides, Faecalibacterium, Capnocytophaga, and Actinomyces was found to be significantly different in patients with LC and controls $(\mathrm{P}<0.05)$. Filifactor, Capnocytophaga, and Veillonella showed diagnosis value for $\mathrm{LC}$ with a ROC value $>0.7$ (54-56). The pathophysiological mechanisms by which LC influences salivary microbiota is currently under investigation. Microbiome dysbiosis may promote LC development and progression through production of toxins and various other pathways, such as affecting long-term immune response.

\section{Others}

Studies on saliva in patients with Langerhans cell histiocytosis (LCH) and cystic fibrosis (CF) have also been reported. These studies found that salivary interleukin-1b (IL-1b)and prostaglandin E2 (PGE2) levels could be used as biomarkers for the diagnosis and evaluation of disease severity of $\mathrm{LCH}$ in children (57), and salivary ions including chloride and sodium could be used for the diagnosis of CF (58). Moreover, gastroesophageal reflux disease (GERD) is associated with several respiratory diseases, for example COPD, asthma, idiopathic pulmonary fibrosis (IPF), and OSA, and it has been reported that salivary pepsin detection could be used to monitor GERD (83-86). Furthermore, therapeutic drug monitoring (TDM) studies on saliva with regard to respiratory diseases also should be mentioned. However, the negative results associated with the levels of theophylline, amikacin, levofloxacin, or tobramycin in salivary sample imply that salivary samples are not suitable for TDM in patients with COPD, TB, and LC $(16,48,49,59)$.

\section{Discussion}

Saliva can be collected in a simple, minimally-invasive, and repeated manner, and is used widely for studying microbiomics, genomics, transcriptomics, proteomics, and metabolomics of respiratory diseases. It showed potential value in the diagnosis, monitoring, and prognosis of respiratory diseases. However, the pathophysiological mechanisms by which respiratory diseases influence the levels of saliva indicators are rarely mentioned. Furthermore, several limitations of saliva test also should be mentioned. Firstly, oral environment is affected by many factors, and a standard protocol for saliva collection and saliva preservation has not been established $(15,44,87)$. Several methods have been reported, such as spitting into in a sterile tube (15), chewing a sterile cotton swab (Salivette) (44), and chewing $1 \mathrm{~g}$ of nonsweet paraffin for 15 minutes to stimulate saliva production (87); however, the influence of these methods on the results has not been studied. Establishing a standard protocol for saliva collection and saliva preservation is a challenge for saliva test in the future. Secondly, recent studies have demonstrated that most biomarkers that are collected from serum and other body fluids used for the diagnosis and treatment of respiratory diseases can also be detected in saliva; although the relationship between levels of indicators in saliva and other samples is reported $(6,41,45,46)$, reference values of various salivary biomarkers have not been established. Establishing reasonable reference values need to be considered in the further studies. Thirdly, most of the results came from cross-sectional study with small samples rather than RCT studies.

In conclusion, the use of salivary biomarkers for the diagnosis, monitoring, and prognosis of respiratory disease is still in its infancy. Multicenter, prospective clinical studies are needed in the future.

\section{Acknowledgments}

Funding: This work was supported by grants from the National Key R\&D Program of China (2018YFC1311900), National Natural Science Foundation of China (82070089, 81770084, 81700084, 81570082), and the Key Research Program of Shanghai Science and Technology Commission (18140903600).

\section{Footnote}

Reporting Checklist: We present the manuscript in accordance with the Narrative Review reporting checklist. Available at http://dx.doi.org/10.21037/jtd-21-202

Peer Review File: Available at http://dx.doi.org/10.21037/jtd21-202 
Conflicts of Interest: All authors have completed the ICMJE uniform disclosure form (available at http://dx.doi. org/10.21037/jtd-21-202). The authors have no conflicts of interest to declare.

Ethical Statement: The authors are accountable for all aspects of the work in ensuring that questions related to the accuracy or integrity of any part of the work are appropriately investigated and resolved.

Open Access Statement: This is an Open Access article distributed in accordance with the Creative Commons Attribution-NonCommercial-NoDerivs 4.0 International License (CC BY-NC-ND 4.0), which permits the noncommercial replication and distribution of the article with the strict proviso that no changes or edits are made and the original work is properly cited (including links to both the formal publication through the relevant DOI and the license). See: https://creativecommons.org/licenses/by-nc-nd/4.0/.

\section{References}

1. Dawes C, Pedersen AM, Villa A, et al. The functions of human saliva: A review sponsored by the World Workshop on Oral Medicine VI. Arch Oral Biol 2015;60:863-74.

2. Carpenter GH. The secretion, components, and properties of saliva. Annu Rev Food Sci Technol 2013;4:267-76.

3. Kaczor-Urbanowicz KE, Wei F, Rao SL, et al. Clinical validity of saliva and novel technology for cancer detection. Biochim Biophys Acta Rev Cancer 2019;1872:49-59.

4. Yang J, Wei F, Schafer C, et al. Detection of tumor cellspecific mRNA and protein in exosome-like microvesicles from blood and saliva. PLoS One 2014;9:e110641.

5. Sun Y, Liu S, Qiao Z, et al. Systematic comparison of exosomal proteomes from human saliva and serum for the detection of lung cancer. Anal Chim Acta 2017;982:84-95.

6. Ding S, Song X, Geng X, et al. Saliva-derived cfDNA is applicable for EGFR mutation detection but not for quantitation analysis in non-small cell lung cancer. Thorac Cancer 2019;10:1973-83.

7. Kaczor-Urbanowicz KE, Martin Carreras-Presas C, Aro $\mathrm{K}$, et al. Saliva diagnostics - Current views and directions. Exp Biol Med (Maywood) 2017;242:459-72.

8. Zhang CZ, Cheng XQ, Li JY, et al. Saliva in the diagnosis of diseases. Int J Oral Sci 2016;8:133-7.

9. Mateos J, Estévez O, González-Fernández Á, et al. Highresolution quantitative proteomics applied to the study of the specific protein signature in the sputum and saliva of active tuberculosis patients and their infected and uninfected contacts. J Proteomics 2019;195:41-52.

10. Ruhl S. The scientific exploration of saliva in the postproteomic era: from database back to basic function. Expert Rev Proteomics 2012;9:85-96.

11. Nie S, Henley WH, Miller SE, et al. An automated integrated platform for rapid and sensitive multiplexed protein profiling using human saliva samples. Lab Chip 2014;14:1087-98.

12. Walt DR, Blicharz TM, Hayman RB, et al. Microsensor arrays for saliva diagnostics. Ann N Y Acad Sci 2007;1098:389-400.

13. Chen X, Dong T, Wei X, et al. Electrochemical methods for detection of biomarkers of Chronic Obstructive Pulmonary Disease in serum and saliva. Biosens Bioelectron 2019;142:111453.

14. Qian K, Wang Y, Hua L, et al. New method of lung cancer detection by saliva test using surface-enhanced Raman spectroscopy. Thorac Cancer 2018;9:1556-61.

15. Zamora-Mendoza BN, Espinosa-Tanguma R, RamírezElías MG, et al. Surface-enhanced raman spectroscopy: A non invasive alternative procedure for early detection in childhood asthma biomarkers in saliva. Photodiagnosis Photodyn Ther 2019;27:85-91.

16. Hendeles L, Burkey S, Bighley L, et al. Unpredictability of theophylline saliva measurements in chronic obstructive pulmonary disease. J Allergy Clin Immunol 1977;60:335-8.

17. Espuela-Ortiz A, Lorenzo-Diaz F, Baez-Ortega A, et al. Bacterial salivary microbiome associates with asthma among african american children and young adults. Pediatr Pulmonol 2019;54:1948-56.

18. Little FF, Delgado DM, Wexler PJ, et al. Salivary inflammatory mediator profiling and correlation to clinical disease markers in asthma. PLoS One 2014;9:e84449.

19. Bowton DL, Seeds MC, Bass DA, et al. Eosinophil cationic protein concentration in saliva does not correlate with eosinophil cationic protein concentration in sputum. Chest 2003;123:372S.

20. Schmekel B, Ahlner J, Malmström M, et al. Eosinophil cationic protein (ECP) in saliva: a new marker of disease activity in bronchial asthma. Respir Med 2001;95:670-5.

21. Popovic M, Fiano V, Fasanelli F, et al. Differentially methylated DNA regions in early childhood wheezing: An epigenome-wide study using saliva. Pediatr Allergy Immunol 2019;30:305-14.

22. Gaber F, Daham K, Higashi A, et al. Increased levels of cysteinyl-leukotrienes in saliva, induced sputum, urine and blood from patients with aspirin-intolerant asthma. 
Thorax 2008;63:1076-82.

23. Patel N, Belcher J, Thorpe G, et al. Measurement of $\mathrm{C}$-reactive protein, procalcitonin and neutrophil elastase in saliva of COPD patients and healthy controls: correlation to self-reported wellbeing parameters. Respir Res 2015;16:62.

24. Ji J, von Schéele I, Bergström J, et al. Compartment differences of inflammatory activity in chronic obstructive pulmonary disease. Respir Res 2014;15:104.

25. Yigla $M$, Berkovich $Y$, Nagler RM, et al. Oxidative stress indices in COPD--Broncho-alveolar lavage and salivary analysis. Arch Oral Biol 2007;52:36-43.

26. Lin M, Li X, Wang J, et al. Saliva Microbiome Changes in Patients With Periodontitis With and Without Chronic Obstructive Pulmonary Disease. Front Cell Infect Microbiol 2020;10:124.

27. Yoshimatsu Y, Tobino K, Sueyasu T, et al. Repetitive Saliva Swallowing Test Predicts COPD Exacerbation. Int J Chron Obstruct Pulmon Dis 2019;14:2777-85.

28. Akpinar ME, Yigit O, Altundag A, et al. Salivary and serum myeloperoxidase in obstructive sleep apnea. J Otolaryngol Head Neck Surg 2012;41:215-21.

29. Tóthová L', Celec P, Mucska I, et al. Short-term effects of continuous positive airway pressure on oxidative stress in severe sleep apnea. Sleep Breath 2019;23:857-63.

30. Yan YR, Zhang L, Lin YN, et al. The Association of Salivary Biomarkers With the Severity of Obstructive Sleep Apnea and Concomitant Hypertension. Am J Med Sci 2019;357:468-73.

31. Ghiciuc CM, Dima Cozma LC, Bercea RM, et al. Restoring the salivary cortisol awakening response through nasal continuous positive airway pressure therapy in obstructive sleep apnea. Chronobiol Int 2013;30:1024-31.

32. Park CS, Guilleminault C, Hwang SH, et al. Correlation of salivary cortisol level with obstructive sleep apnea syndrome in pediatric subjects. Sleep Med 2013;14:978-84.

33. Bublitz MH, Monteiro JF, Caraganis A, et al. Obstructive Sleep Apnea in Gestational Diabetes: A Pilot Study of the Role of the Hypothalamic-Pituitary-Adrenal Axis. J Clin Sleep Med 2018;14:87-93.

34. Patacchioli FR, Tabarrini A, Ghiciuc CM, et al. Salivary biomarkers of obstructive sleep apnea syndrome in children. Pediatr Pulmonol 2014;49:1145-52.

35. Papaioannou I, Twigg GL, Kemp M, et al. Melatonin concentration as a marker of the circadian phase in patients with obstructive sleep apnoea. Sleep Med 2012;13:167-71.

36. Zheng H, Li R, Zhang J, et al. Salivary biomarkers indicate obstructive sleep apnea patients with cardiovascular diseases. Sci Rep 2014;4:7046.

37. Traxdorf M, Wendler O, Tziridis K, et al. S100B in serum and saliva: a valid invasive or non-invasive biomarker in obstructive sleep apnea? Eur Rev Med Pharmacol Sci 2016;20:4766-74.

38. Roedig JJ, Phillips BA, Morford LA, et al. Comparison of BMI, AHI, and apolipoprotein E 4 (APOE- 4) alleles among sleep apnea patients with different skeletal classifications. J Clin Sleep Med 2014;10:397-402.

39. To KK, Tsang OT, Yip CC, et al. Consistent Detection of 2019 Novel Coronavirus in Saliva. Clin Infect Dis 2020;71:841-3.

40. Azzi L, Carcano G, Gianfagna F, et al. Saliva is a reliable tool to detect SARS-CoV-2. J Infect 2020;81:e45-50.

41. Tsai CM, Tang KS, Cheng MC, et al. Use of saliva sample to detect C-reactive protein in children with pneumonia. Pediatr Pulmonol 2020;55:2457-62.

42. Omran A, Ali M, Saleh MH, et al. Salivary C-reactive protein and mean platelet volume in diagnosis of late-onset neonatal pneumonia. Clin Respir J 2018;12:1644-50.

43. Klein Kremer A, Kuzminsky E, Bentur L, et al. Salivary and serum analysis in children diagnosed with pneumonia. Pediatr Pulmonol 2014;49:569-73.

44. Jacobs R, Maasdorp E, Malherbe S, et al. Diagnostic Potential of Novel Salivary Host Biomarkers as Candidates for the Immunological Diagnosis of Tuberculosis Disease and Monitoring of Tuberculosis Treatment Response. PLoS One 2016;11:e0160546.

45. Namuganga AR, Chegou NN, Mubiri P, et al. Suitability of saliva for Tuberculosis diagnosis: comparing with serum. BMC Infect Dis 2017;17:600.

46. Phalane KG, Kriel M, Loxton AG, et al. Differential expression of host biomarkers in saliva and serum samples from individuals with suspected pulmonary tuberculosis. Mediators Inflamm 2013;2013:981984.

47. Jacobs R, Tshehla E, Malherbe S, et al. Host biomarkers detected in saliva show promise as markers for the diagnosis of pulmonary tuberculosis disease and monitoring of the response to tuberculosis treatment. Cytokine 2016;81:50-6.

48. van den Elsen SHJ, Akkerman OW, Huisman JR, et al. Lack of penetration of amikacin into saliva of tuberculosis patients. Eur Respir J 2018;51:1702024.

49. Ghimire S, Maharjan B, Jongedijk EM, et al. Evaluation of Saliva as a Potential Alternative Sampling Matrix for Therapeutic Drug Monitoring of Levofloxacin in Patients with Multidrug-Resistant Tuberculosis. Antimicrob Agents Chemother 2019;63:e02379-18. 
50. Wei F, Lin CC, Joon A, et al. Noninvasive saliva-based EGFR gene mutation detection in patients with lung cancer. Am J Respir Crit Care Med 2014;190:1117-26.

51. Pu D, Liang H, Wei F, et al. Evaluation of a novel salivabased epidermal growth factor receptor mutation detection for lung cancer: A pilot study. Thorac Cancer 2016;7:428-36.

52. Zhang L, Xiao H, Zhou H, et al. Development of transcriptomic biomarker signature in human saliva to detect lung cancer. Cell Mol Life Sci 2012;69:3341-50.

53. Xiao H, Zhang L, Zhou H, et al. Proteomic analysis of human saliva from lung cancer patients using twodimensional difference gel electrophoresis and mass spectrometry. Mol Cell Proteomics 2012;11:M111.012112.

54. Wang K, Huang Y, Zhang Z, et al. A Preliminary Study of Microbiota Diversity in Saliva and Bronchoalveolar Lavage Fluid from Patients with Primary Bronchogenic Carcinoma. Med Sci Monit 2019;25:2819-34.

55. Zhang W, Luo J, Dong X, et al. Salivary Microbial Dysbiosis is Associated with Systemic Inflammatory Markers and Predicted Oral Metabolites in Non-Small Cell Lung Cancer Patients. J Cancer 2019;10:1651-62.

56. Yan X, Yang M, Liu J, et al. Discovery and validation of potential bacterial biomarkers for lung cancer. Am J Cancer Res 2015;5:3111-22.

57. Preliasco VF, Benchuya C, Pavan V, et al. IL-1 beta and PGE2 levels are increased in the saliva of children with Langerhans cell histiocytosis. J Oral Pathol Med 2008;37:522-7.

58. Gonçalves AC, Marson FA, Mendonça RM, et al. Saliva as a potential tool for cystic fibrosis diagnosis. Diagn Pathol 2013;8:46.

59. Madsen V, Lind A, Rasmussen M, et al. Determination of tobramycin in saliva is not suitable for therapeutic drug monitoring of patients with cystic fibrosis. J Cyst Fibros 2004;3:249-51.

60. Koh GC, Shek LP, Goh DY, et al. Eosinophil cationic protein: is it useful in asthma? A systematic review. Respir Med 2007;101:696-705.

61. Gomez JL. Epigenetics in Asthma. Curr Allergy Asthma Rep 2019;19:56.

62. Xu CJ, Söderhäll C, Bustamante M, et al. DNA methylation in childhood asthma: an epigenome-wide meta-analysis. Lancet Respir Med 2018;6:379-88.

63. Reese SE, Xu CJ, den Dekker HT, et al. Epigenome-wide meta-analysis of DNA methylation and childhood asthma. J Allergy Clin Immunol 2019;143:2062-74.

64. Faner R, Tal-Singer R, Riley JH, et al. Lessons from
ECLIPSE: a review of COPD biomarkers. Thorax 2014;69:666-72.

65. Dong T, Santos S, Yang Z, et al. Sputum and salivary protein biomarkers and point-of-care biosensors for the management of COPD. Analyst 2020;145:1583-604.

66. Benjafield AV, Ayas NT, Eastwood PR, et al. Estimation of the global prevalence and burden of obstructive sleep apnoea: a literature-based analysis. Lancet Respir Med 2019;7:687-98.

67. Ghiciuc CM, Dima-Cozma LC, Bercea RM, et al. Imbalance in the diurnal salivary testosterone/cortisol ratio in men with severe obstructive sleep apnea: an observational study. Braz J Otorhinolaryngol 2016;82:529-35.

68. Corstjens PL, Abrams WR, Malamud D, et al. Saliva and viral infections. Periodontol 2000 2016;70:93-110.

69. Silva J, Lucas C, Sundaram M, et al. Saliva viral load is a dynamic unifying correlate of COVID-19 severity and mortality. medRxiv 2021. [Epub ahead of print]. doi: 10.1101/2021.01.04.21249236.

70. Ku CW, Shivani D, Kwan JQT, et al. Validation of selfcollected buccal swab and saliva as a diagnostic tool for COVID-19. Int J Infect Dis 2021;104:255-61.

71. Rao M, Rashid FA, Sabri FSAH, et al. COVID-19 screening test by using random oropharyngeal saliva. J Med Virol 2021;93:2461-6.

72. Santos CN, Rezende KM, Oliveira Neto NF, et al. Saliva: an important alternative for screening and monitoring of COVID-19 in children. Braz Oral Res 2020;34:e0125.

73. Fernandes LL, Pacheco VB, Borges L, et al. Saliva in the Diagnosis of COVID-19: A Review and New Research Directions. J Dent Res 2020;99:1435-43.

74. Czumbel LM, Kiss S, Farkas N, et al. Saliva as a Candidate for COVID-19 Diagnostic Testing: A Meta-Analysis. Front Med (Lausanne) 2020;7:465.

75. Hung KF, Sun YC, Chen BH, et al. New COVID-19 saliva-based test: How good is it compared with the current nasopharyngeal or throat swab test? J Chin Med Assoc 2020;83:891-4.

76. Bágyi K, Haczku A, Márton I, et al. Role of pathogenic oral flora in postoperative pneumonia following brain surgery. BMC Infect Dis 2009;9:104.

77. Gianchecchi E, Manenti A, Kistner O, et al. How to assess the effectiveness of nasal influenza vaccines? Role and measurement of sIgA in mucosal secretions. Influenza Other Respir Viruses 2019;13:429-37.

78. Scriba TJ, Coussens AK, Fletcher HA, et al. Human Immunology of Tuberculosis. Microbiol Spectr 2017.

79. Song M, Chan AT, Sun J, et al. Influence of the Gut 
Microbiome, Diet, and Environment on Risk of Colorectal Cancer. Gastroenterology 2020;158:322-40.

80. McAllister F, Khan MAW, Helmink B, et al. The Tumor Microbiome in Pancreatic Cancer: Bacteria and Beyond. Cancer Cell 2019;36:577-9.

81. Nagasaka M, Sexton R, Alhasan R, et al. Gut microbiome and response to checkpoint inhibitors in non-small cell lung cancer-A review. Crit Rev Oncol Hematol 2020;145:102841.

82. Peterson SN, Bradley LM, Ronai ZA, et al. The gut microbiome: an unexpected player in cancer immunity. Curr Opin Neurobiol 2020;62:48-52.

83. Savarino E, Carbone R, Marabotto E, et al. Gastrooesophageal reflux and gastric aspiration in idiopathic pulmonary fibrosis patients. Eur Respir J 2013;42:1322-31.
84. Strugala V, Dettmar PW, Bittenglova R, et al. Use of pepsin detection to identify airways reflux in a range of pulmonary diseases. Clin Respir J 2017;11:666-7.

85. Laohasiriwong S, Johnston N, Woodson BT, et al. Extraesophageal reflux, NOSE score, and sleep quality in an adult clinic population. Laryngoscope 2013;123:3233-8.

86. Iannella G, Vicini C, Polimeni A, et al. Laryngopharyngeal Reflux Diagnosis in Obstructive Sleep Apnea Patients Using the Pepsin Salivary Test. Int J Environ Res Public Health 2019;16:2056.

87. del-Río-Navarro BE, Corona-Hernández L, FragosoRíos R, et al. Effect of salmeterol and salmeterol plus beclomethasone on saliva flow and IgA in patients with moderate-persistent chronic asthma. Ann Allergy Asthma Immunol 2001;87:420-3.
Cite this article as: Li CX, Zhang L, Yan YR, Ding YJ, Lin YN, Zhou JP, Li N, Li HP, Li SQ, Sun XW, Li QY. A narrative review of exploring potential salivary biomarkers in respiratory diseases: still on its way. J Thorac Dis 2021;13(7):4541-4553. doi: 10.21037/jtd-21-202 